\title{
Investigation the gas-solid flows in a circulating fludisied bed with multi-cyclone separators by electrical capacitance tomography
}

Link to publication record in Manchester Research Explorer

Citation for published version (APA):

Yang, W., Wang, H., \& Qiu, G. (2013). Investigation the gas-solid flows in a circulating fludisied bed with multicyclone separators by electrical capacitance tomography. In host publication IEEE.

\section{Published in:}

host publication

\section{Citing this paper}

Please note that where the full-text provided on Manchester Research Explorer is the Author Accepted Manuscript or Proof version this may differ from the final Published version. If citing, it is advised that you check and use the publisher's definitive version.

\section{General rights}

Copyright and moral rights for the publications made accessible in the Research Explorer are retained by the authors and/or other copyright owners and it is a condition of accessing publications that users recognise and abide by the legal requirements associated with these rights.

\section{Takedown policy}

If you believe that this document breaches copyright please refer to the University of Manchester's Takedown Procedures [http://man.ac.uk/04Y6Bo] or contact uml.scholarlycommunications@manchester.ac.uk providing relevant details, so we can investigate your claim.

\section{OPEN ACCESS}




\section{Investigation of the gas-solid flows in a circulating fludisied bed with multi-cyclone separators by electrical capacitance tomography}

\author{
Haigang Wang, Guizhi Qiu \\ Institute of Engineering Thermophysics \\ Chinese Academy of Sciences \\ PO Box 2706 \\ Beijing, 100190, China \\ wanghaig@hotmail.com
}

\author{
Wuqiang Yang \\ School of Electrical and Electronic Engineering \\ The University of Manchester \\ Sackville Street \\ Manchester M60 1QD, UK \\ Wuqiang.yang@manchester.ac.uk
}

\begin{abstract}
To investigate the gas-solid flows in a circulating fluidised bed with multi-cyclone separators, a circular ECT sensor and rectangular ECT sensor are designed and used to measure the solids distribution in a cross-section in the inlet and standpipe of cyclone separator respectively. The rectangular ECT sensor has 12 electrodes with two in each shorter side and four in each longer side. The circular ECT sensor has 8 electrodes. For image reconstruction, sensitivity maps have been calculated using a simulation package, Maxwell from Ansoft. Dynamics test of CFB processes with different fluidisation velocity are given both in the inlet and downwards standpipe of the cyclone. ECT test results are given and analyzed and compared with pressure measurement results.
\end{abstract}

Keywords - CFB, ECT, Cyclone separators, Rectangular sensor

\section{INTRODUCTION}

Circulating fluidised bed (CFB) combustion technology combined with a high efficiency gas-solid separation circulation is one of the key factors to reducing air emissions and the effect on global warming (Reh 2003). The development of CFB technology is continued to offer up to 600-800 MWe capacities with ultra-super high steam parameters (Luo et al. 2005). In the meanwhile, technology is being developed to provide flexible operation for air and oxy-combustion to capture carbon.

To meet the demand for optimised operation parameters and large thermal capacity, to achieve high combustion efficiency, and to reduce limestone consumption and high sulphur capture efficiency, high efficiency gas-solids separation is a key issue (Morin et al. 2003). Due to the decrease in centrifugal force with the increase of cyclone diameter, however, the separation efficiency decreases with the scaling-up of CFB boiler (Hack et al. 2008). To deal with the above problem, several small cyclones may be used instead of one large cyclone. A problem with several small cyclones is non-uniform solids distribution between the cyclones, which would have strong effect on the coal combustion process and pollution emission (Yue et al.
2008). Further, the non-uniform solids flux will result in the un-balance distribution of heat flux along the heat transfer surface. The difference of solids concentration can be as high as $17 \%$ between different cyclone separators (Li et al. 2009). To overcome the non-uniform distribution, some methods has been reported and patented. ALSTOM proposed a type of multi-cyclone separator system, which can achieve uniform solids distribution in different cyclone separators based on cold test in a CFB with the scale of 0.45 $\mathrm{m}^{2}$ in square cross section with a height of $10.5 \mathrm{~m}$ (Armistead et al. 2002). Foster-Wheeler proposed to additional membrane tube wall on the top of boiler chamber to provide uniform solids distribution among separators. Tsinghua University and Dongfang Boiler (Group) Co. Ltd. designed a type of non-uniform separators and cold flow test and CFD simulation have been carried out (Liu et al. 2009).

To understand the hydrodynamic behaviour of super-high pressure CFB, a cold CFB test rig with symmetrical arrangements of six cyclone separators on the top of the boiler, three separators in each side has been built in the Institute of Engineering Thermophysics, Chinese Academy of Sciences. The objective of this research is to investigate the cold gas-solids distribution among the six cyclones by ECT measurement. The experiment includes the effect of fluidisation velocity and boiler load (initial material weight) on the solids flux through the inlet of cyclones and solids concentration as well as flow rate recirculation to the chamber in the standpipe. ECT measurement results will be validated by conventional method results including pressure measurement.

\section{ECT SENSOR}

Fig. 1 shows the ECT sensors used in the research. For the rectangular ECT sensor, there are two electrodes in each shorter side and four in each longer side. The length of electrodes along the flow direction is $5 \mathrm{~cm}$. Theoretically, the electrode should be longer in the flow direction than the mean dimension of the cross section to reduce the $3 \mathrm{D}$ fringe

The authors would like to thank the National Natural Science Foundation of China (No. 61072001) to support this work. 
effect (Yang 2010). However, due to the limitation in space, the maximum length of the ECT sensor can be $5 \mathrm{~cm}$ only. The circular ECT sensor as shown in Fig.1 (b) has 8 electrodes. There are total 6 circular ECT sensors mounted in the standpipe and located $20 \mathrm{~cm}$ above the U-loop. The measurement system is AC-based ECT system provided by ECT Instruments Ltd (UK) with a data acquisition rate up to 150 frames/second for a twelve electrodes sensor (Yang and York 1999).

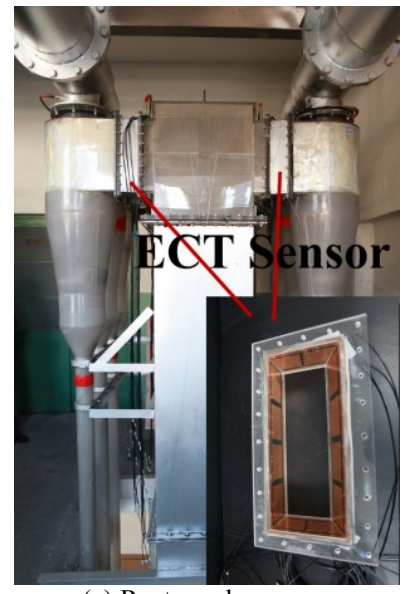

(a) Rectangular sensor

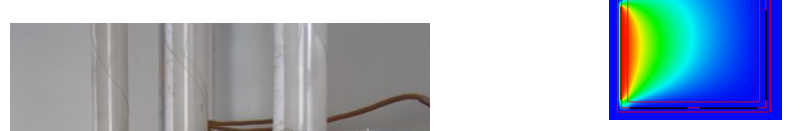

(a) Electrode 1 energized

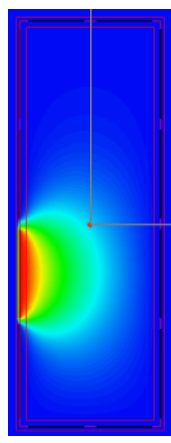

(b) Electrode energized

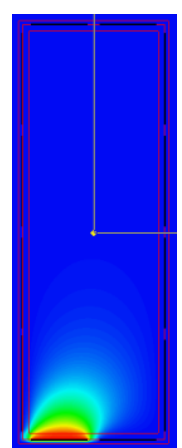

(c) Electrode 11 energized
Fig. 1 ECT sensor design and construction

\section{CALCULATION OF SENSITIVITY MAPS}

For the ECT sensor as shown in Fig. 1, the potential distributions are solved by 2D modelling based on a finite element method (FEM) and by simulation using a software package, Maxwell from Ansoft. For modelling, it is important to select an appropriate mesh to minimise the error. The mesh size and parameters can be set manually. In Maxwell, adaptive mesh generation can be selected for the model. It identifies the regions where high resolution is needed. In the ECT sensor model high resolution meshes are required in the gap between the adjacent electrodes and between the measurement electrodes and earthed screen due to high gradients of potential. Fig. 2 shows three typical potential distributions with electrode 1,2 and 12 energized respectively.

The sensitivity map of electrode pair $i-j$ at a spatial location $(x, y)$ can now be calculated by vector multiplication of two electric fields, which are normal to the potential distributions.

$$
S_{i, j}(x, y)=-\oint_{p(x, y)} \frac{\overrightarrow{E_{i}}}{V_{i}} \cdot \frac{\overrightarrow{E_{j}}}{V_{j}} \cdot d v
$$

where $E(x, y)$ is the electric field when an excitation voltage $V_{i}$ is applied to electrode $i$ while all other electrodes remain at the earth potential, and $p(x, y)$ is the volume of the cell at $(x, y)$. Fig. 3 shows some typical sensitivity maps.
Fig. 2 Typical potential distributions

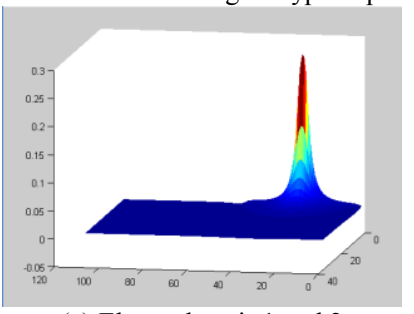

(a) Electrode pair 1 and 2

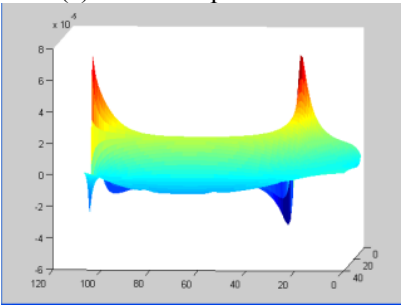

(c) Electrode pair 1 and 52

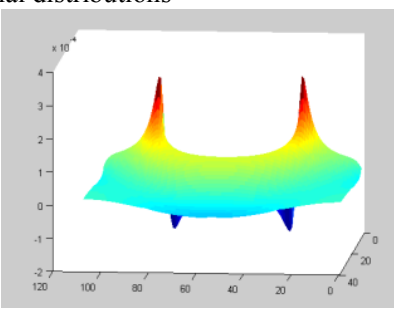

(b) Electrode pair 1 and 4

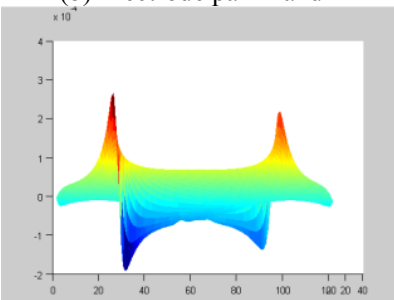

(d) Electrode pair 1 and 7
Figure 3 Typical sensitivity maps

\section{TEST RESULTS AND ANALYSIS}

The CFB chamber is $5.8 \mathrm{~m}$ tall and has a cross-section of $0.92 \times 0.42 \mathrm{~m}$. There are three cyclone separators in each side on the top of the boiler chamber as shown in Fig.1. The primary air is fed through a windbox below the air distributor in a range of $2 \sim 6 \mathrm{~m} / \mathrm{s}$. The test material is sand with the mean diameter of $500 \mu \mathrm{m}$ and packed density of $1635 \mathrm{~kg} / \mathrm{m}^{3}$. The initial material load is $220 \mathrm{~kg}$ and static bed height is $50 \mathrm{~cm}$. The fluidization velocity is in the range of $3.23 \mathrm{~m} / \mathrm{s}$ and $4.67 \mathrm{~m} / \mathrm{s}$. Landweber iteration algorithm (Yang et al. 1999) is used to image reconstruction. During the measurement, the bed is fluidised and run for 5 minutes and continuous recorded the capacitance for 10 minutes both in the inlet and standpipe of the cyclone.

\section{A. Results analysis in the standpipe}

Fig. 4 gives the reconstructed image in the cross-section in the standpipe with different fluidisation flow rate. The solids voidage is in the range of $0 \% \sim 2.0 \%, 2 \% \sim 3.0 \%, 3 \% \sim$ $6.0 \%$ when the flow rate is $4500 \mathrm{~m}^{3} / \mathrm{h}, 5500 \mathrm{~m}^{3} / \mathrm{h}$ and 6500 
$\mathrm{m}^{3} / \mathrm{h}$ respectively. Fig. 5 shows the averaged capacitance and solids voidage profile with different flow rate for one of the standpipe. As can be seen from those images, the solid flow in the standpipe is typical annular flow due to the strong swirl effect in the cyclone separator. The solid concentration increases with the increase of fluidisation air through the standpipe. This can be seen clearly from Fig. 5 in terms of capacitance and averaged solids voidage.

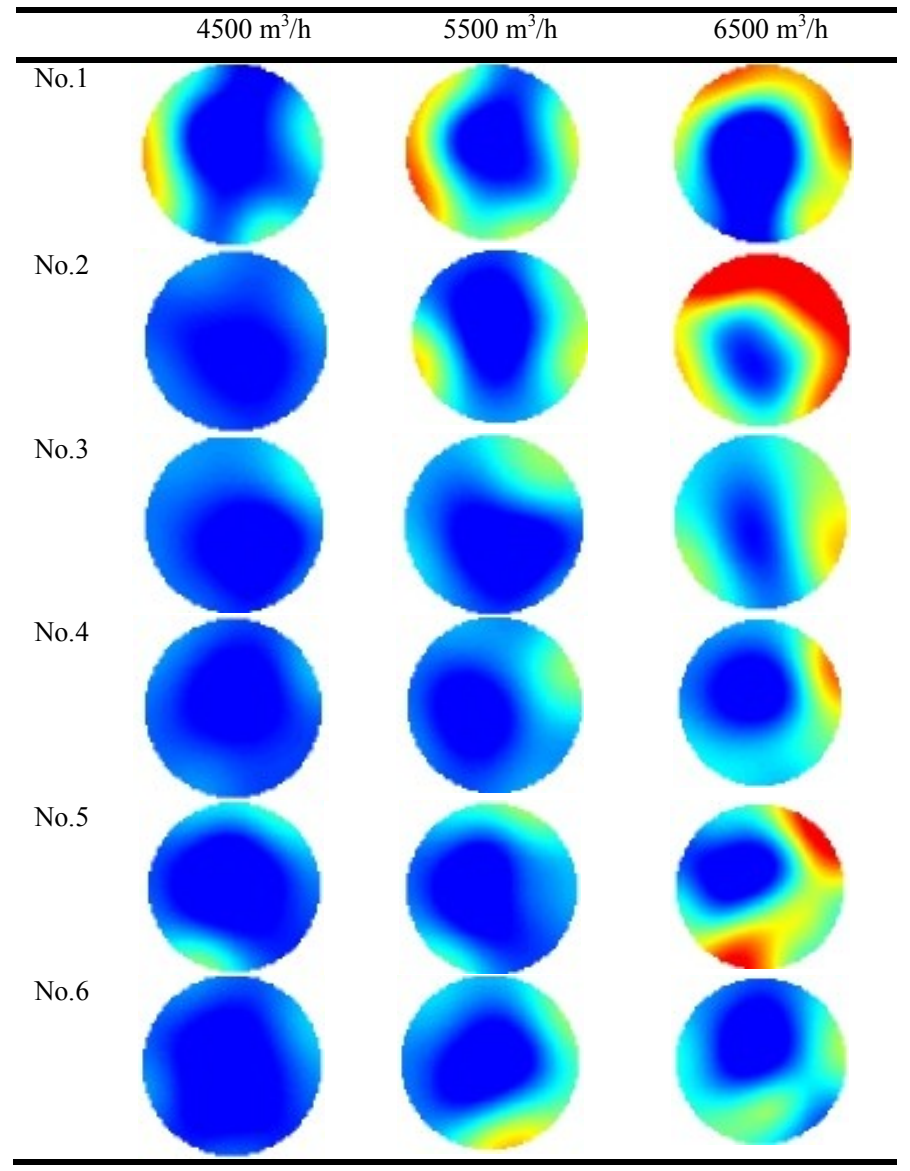

Fig. 4 Image reconstruction with different fluidisation flow rate

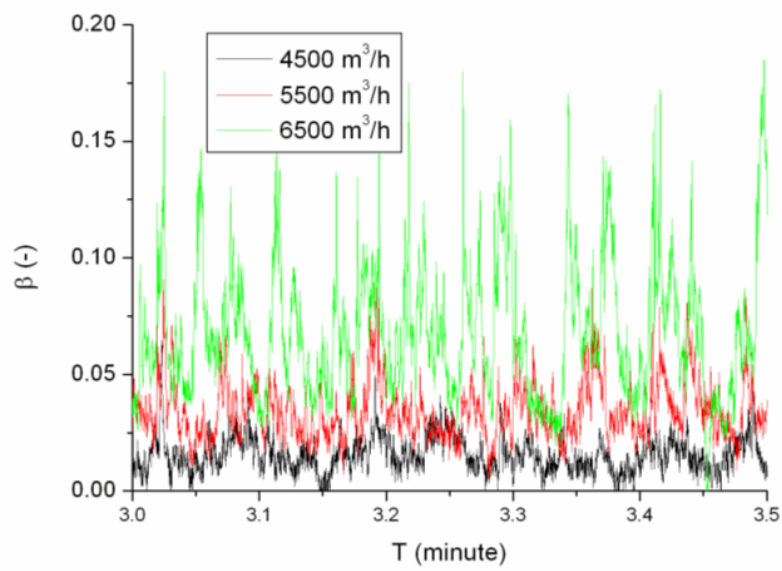

(a) Capacitance

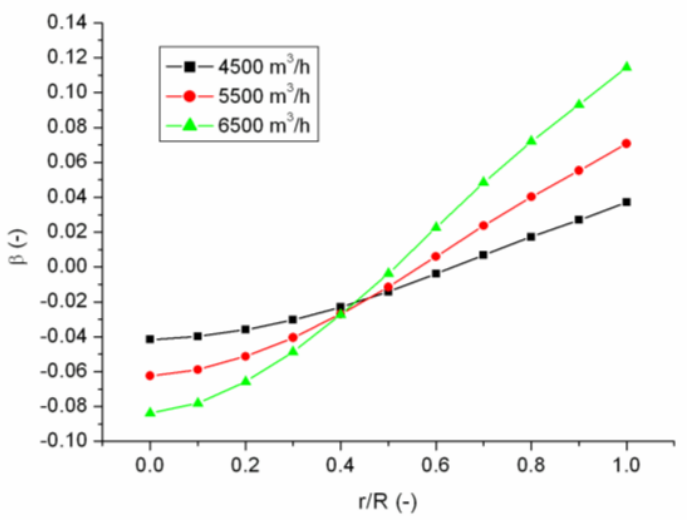

(b) Averaged solid concentration

Fig. 5 Averaged solid concentration profile with different fluidisation flowrate

\section{B. Results analysis in the inlet of cyclone}

Fig. 6 gives the image reconstruction results for all of the cyclone inlets during the test. It is clearly shows that the sands accumulated in the lower corner of the cyclone inlet due to low velocity in these areas. Fig.7 gives the comparison results with real camera recorded photo. In real industrial CFB design, it is necessary to optimum design the cyclone inlet in terms of inlet angle and cross-section area to achieve high solid separation efficiency.

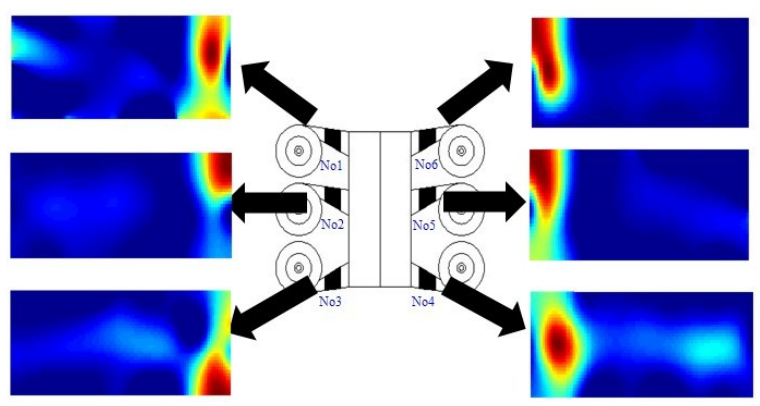

Fig. 6 Image reconstruction in the cyclone inlet
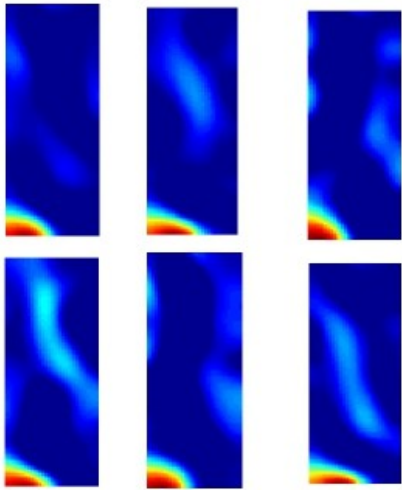

(a) Image

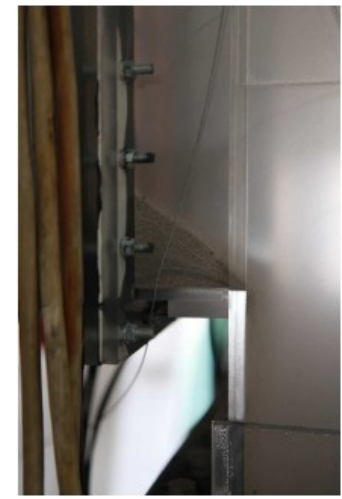

(b) Photo

Fig. 7 Image reconstruction in the cyclone inlet 


\section{Solids concentration and flux distribution}

Table 1 summary the means solids concentration in the inlet of cyclone with different flow condition. Fig. 8 gives the average solids concentration in the three inlets for one side of the CFB and solids flux in the standpipe based on weight and time measured method.

Tab.1 Averaged solids concentration in the cross-sectional area

\begin{tabular}{ccccc}
\hline $\begin{array}{c}\text { Material } \\
(\mathrm{kg})\end{array}$ & $\begin{array}{c}\text { Velocity } \\
(\mathrm{m} / \mathrm{s})\end{array}$ & No.4 & No.5 & No.6 \\
\hline 220 & 3.23 & 0.074 & 0.044 & 0.060 \\
220 & 3.95 & 0.074 & 0.071 & 0.070 \\
220 & 4.67 & 0.113 & 0.076 & 0.070 \\
270 & 3.23 & 0.077 & 0.040 & 0.064 \\
270 & 3.95 & 0.088 & 0.059 & 0.069 \\
270 & 4.67 & 0.111 & 0.072 & 0.074 \\
\hline
\end{tabular}

From table 1 and Fig.8, we can see that the average solids concentration and solids flux in the standpipe increases with the increase of fluidisation flow rate. Meanwhile, the distribution of the above parameters is non-uniform among the three standpipes in the same side of the CFB chamber.

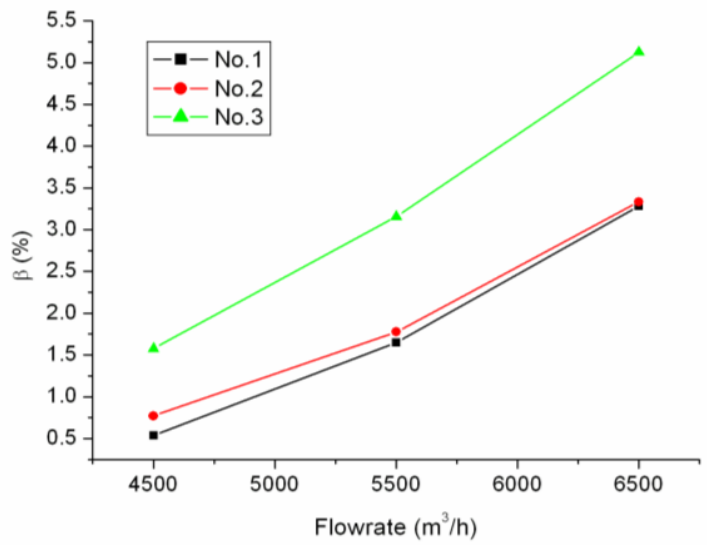

(a) Averaged solid concentration

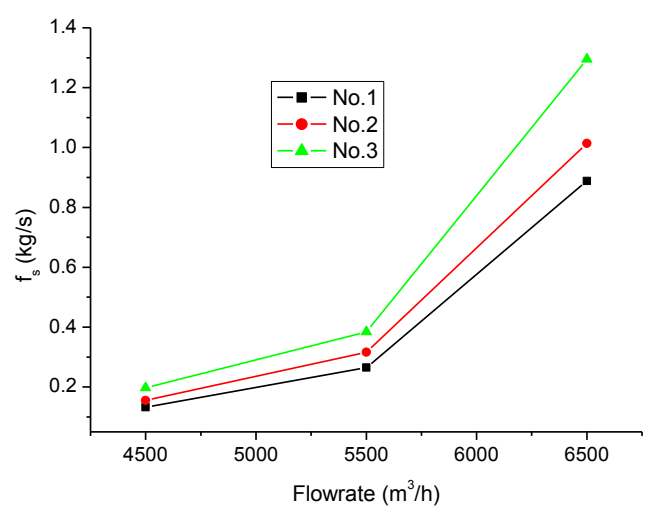

(b) Flowrate

Fig. 8 Averaged solid concentration and flowrate in the standpipe with fluidisation flow rate
Fig.9 gives the averaged solid concentration in the three cyclone inlets profile with different flow rate. It can be seen from the curves that the distribution is non-uniform among the three inlets, i.e. with high value in the corner side and low value in the middle.

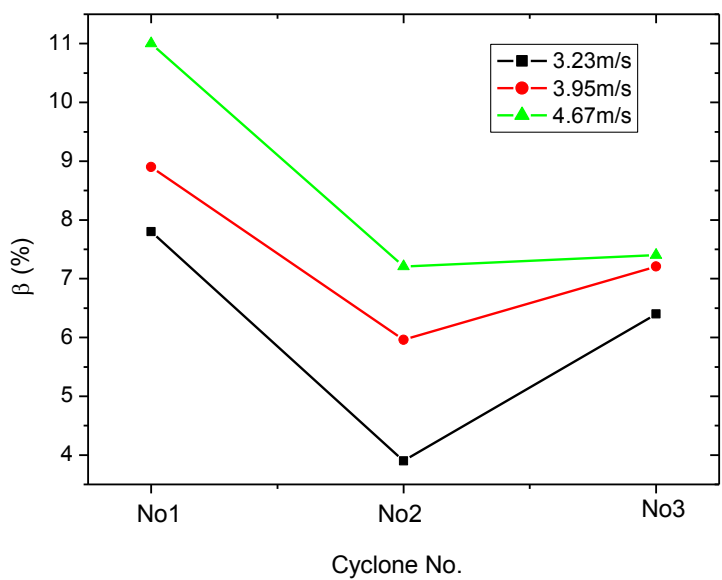

Fig. 9 Averaged solid concentrations in the standpipe with different fluidisation velocity

\section{CONCLUSIONS AND FUTURE WORK}

The gas-solids hydrodynamic behaviour is one of the key issues to scale up a circulating fluidised bed (CFB) from small scale to large scale with multi-cyclone separators system. To investigate the solids distribution in a large scale CFB with six cyclone separators, electrical capacitance tomography is used to measure the solids concentration in the inlet and standpipe of cyclone. Rectangular ECT sensors and circular sensors have been designed and used to measure the solids distribution in a cross-section in the inlet and standpipe of cyclone. Dynamic test with different fluidisation velocity and initial material load are given and analyzed. The preliminary test results show that the solids distribution of the cold model with axis-symmetrically arrangement of cyclones can be measured in different bed inventories and superficial velocities. The measurement result provides valuable information for the scaling up a super-critical pressure circulating fluidised bed with multicyclone separators.

\section{ACKNOWLEDGEMENTS}

The authors would like to thank the National Natural Science Foundation of China (No. 61072001) to support this work.

\section{REFERENCES}

[1] Armistead T.F., Schwieger R. and Reina P. (2002), Boiler technology pursues goals of efficiency and lower emissions-circulating fluidised- 
bed equipment pushes size limits. In: Power \& industrialPOWERPLANTS, 2002.

[2] Hack H., Hotta A., Kettunen A. and Eriksson T. (2008), Ultrasuperhigh CFB technology to meet the challenge of climate change, Foster Wheeler Energia Oy, Finland, 2008.

[3] Li Z.G., Liu Z.C., He J., Na Y.J. and LV Q.G. (2009), Influence of Inlet Duct Layouts on Cyclone Performance, Proceedings of CSEE, 2009, 29, pp 1-7.

[4] Liu Z.C., Sun Y.K., Na Y.J., Bao S.L., Shao J.Z., Guo J.S., Xiao F. and Wang D.F. (2009), Numerical simulation of cyclones arrangements of $600 \mathrm{MW}$ superhigh CFB boiler, Journal of Engineering Thermophysics, 30, pp 1949-1952.

[5] Luo Z.Y. and Cen K.F. (2005), Research and development on circulating fluidised combustion technology in China. Proceedings of the 8th International Conference on Circulating Fluidised Beds, Hangzhou, China, 2005, pp 56-67.
[6] Morin J.X. (2003), Recent Alstom power large CFB and scale up aspects including steps to superhigh, 47th International Energy Agency Workshop on Large Scale CFB, Zlotnicki, Poland, 2003.

[7] Reh L. (2003), Development potentials and research needs in circulating fluidised bed combustion, China Particulology, 1, pp 185 200.

[8] Yang W.Q. (2010), Design of electrical capacitance tomography sensors, Meas. Sci. Technol., 21 paper no. 042001.

[9] Yang W.Q. and York T.A., (1999), New AC-based capacitance tomography system, IEE Proc.-Sci. Meas. Technol., 146, pp 47-53.

[10] Yang W Q, Spink D M, York T A and McCann H (1999), An image reconstruction algorithm based on Landweber iteration method for capacitance tomography, Meas. Sci. Technol., 10, pp 1065-1069.

[11] Yue G.X., Yang H.R., Nie L., Wang Y. and Zhang H.(2008), Hydrodynamics of 300 MWe and 600 MWe CFB boilers with asymmetric cyclone layout, Circulating Fluidised Bed Technology IX, May 13-16, 2008, Germany. 